\title{
O Museu do Pão e o Caminho dos Moinhos: preexistência, intervenção e produção do lugar regional
}

\section{Roberta Krahe Edelweiss}

Professora do Programa de Pós-Graduação em Arquitetura e Urbanismo - Mestrado Associado UniRitter/Mackenzie

Contato: robertaedelweiss@gmail.com

\section{Fábio Bortoli}

Professor do Programa de Pós-Graduação em Arquitetura e Urbanismo - Mestrado Associado UniRitter/Mackenzie Contato: fabiobortoliarq@gmail.com

\section{Carlla Portal Volpatto}

Mestranda pelo Programa de Pós-Graduação em Arquitetura e Urbanismo - Mestrado Associado UniRitter/Mackenzie Contato: carllavolpatto@gmail.com

\section{RESUMO}

O artigo apresenta, a partir do estudo de caso do Museu do Pão, a estratégia de produção do lugar regional por meio da intervenção arquitetônica. Para tanto, abordam-se os conceitos de metástase positiva, acupuntura e placemaking, relacionando a escala territorial e a memória através da intervenção arquitetônica. Parte-se da escala territorial, apresentando, primeiramente, um panorama cultural do Caminho dos Moinhos e identificando o Museu do Páo como uma primeira iniciativa no caminho da conservação da memória cultural.

Palavras-chave: Caminho dos Moinhos, Museu do Pão, metástase positiva, acupuntura, placemaking.

\section{ABSTRACT}

The article presents the case study of the Museu do Páo as a strategy of the regional place production through the architectural intervention. For that, the concepts of positive metastasis, acupuncture and placemaking are discussed, relating territorial scale and memory through the rearchitecture. It starts from the territorial scale, presenting, first, a cultural panorama of the Caminho Moinhos and identifying the Museu do Pão as a first initiative in the way of the conservation of the cultural memory.

Key-words: Caminho dos Moinhos, Museu do Pão, positive metastasis, acupunture, placemaking 


\section{Introdução}

$\mathrm{O}$ artigo aborda o lugar de memória através da intervenção em preexistências e da produção de um conjunto de lugares regionalizados. A partir do exemplo do Museu do Páo e do Caminho dos Moinhos, que representam a chegada da colonização italiana na serra gaúcha, apresenta-se o estudo de caso.

O Caminho dos Moinhos pode ser analisado não só como um lugar de memória, mas também a partir de um ponto de vista territorial, visto que este gera uma modificação benéfica para o seu entorno. Neste sentido, os termos "acupuntura" e "metástase positiva" apresentam-se como uma possível abordagem ao tema relacionando a reutilização de preexistências dotadas de alto potencial simbólico com seu efeito positivo na criação de lugares que se vinculam ao contexto regional pela intervenção do Escritório Brasil Arquitetura.

O objetivo desse artigo é mostrar como a revitalização de preexistências pode ser encarada como resgate de lugares da memória e transformação para o desenvolvimento de uma cidade e de uma regiáo, por meio de estratégias articuladas de arquitetura e urbanismo. Para tal, o artigo está organizado da seguinte maneira: a seção $A$ preexistência como estratégia de produção do lugar regional apresenta, uma possível abordagem teórico-metodológica; a sessão Caminho dos Moinhos aborda o caminho dos moinhos como estratégia regional, a sessão Museu do Pão apresenta uma breve descrição do museu; por fim, a Conclusão apresenta a relação entre os termos desenvolvidos ao longo do artigo e a análise do estudo de caso.
2. A preexistência como estratégia de produção do lugar regional

Intervençôes de projeto de arquitetura e urbanismo em preexistências têm sido usadas para proporcionar o resgate da memória de lugares e, através desse resgate a requalificaçáo de bairros, cidades e regióes. $\mathrm{O}$ potencial dessas intervençóes em causar efeitos positivos é explorado em formulaçôes teóricas recentes. Uma das mais conhecidas é "acupuntura urbana", conceito criado primeiramente pelo arquiteto finlandês Marco Casagrande, que combinou o desenho urbano com a tradicional teoria médica chinesa da acupuntura. No Brasil, o conceito está associado ao livro de mesmo nome do arquiteto e urbanista Jaime Lerner, que o utiliza para defender a melhoria das cidades através de pequenas intervençóes que irradiam efeitos positivos. Assim, a acupuntura urbana atuaria em intervençôes pontuais na tessitura urbana para sanar a dor de forma instantânea, eficaz e funcional. Lerner afirma em seu livro:

Acredito quealgumas magias da medicina podem, e devem ser aplicadas às cidades, pois muitas delas estão doentes, algumas quase em estado terminal. Assim como a medicina necessita da interação entre médico e paciente, em urbanismo também é preciso fazer a cidade reagir. Cutucar uma área de tal maneira que ela possa ajudar a curar, melhorar, criar reaçóes positivas e em cadeia. É indispensável intervir para revitalizar, fazer o organismo trabalhar de outra maneira (LERNER, 2011, p. 7).

Efeito positivo alastrado, causado por intervenção 
relativamente pequena, pontual, conforme explica Alcalá (2006), seria o que o arquiteto cataláo Oriol Bohigas, ao se referir à requalificaçáo dos espaços públicos de Barcelona, chamou de "efeito metástase" no sentido positivo. Ocorreria "onde a intervenção pontual sobre o espaço público terminará produzindo um efeito de regeneração em cadeia sobre seu entorno imediato" (ALCALÁ, 2006, p. 86), desde que com a necessária estratégia de eleição de um lugar apropriado, nevrálgico, onde os impactos sejam mais rápidos e eficazes.

Esse termo se aplica ao Caminho dos Moinhos, pois a região do Vale do Taquari na qual se encontram os moinhos, construídos pelos imigrantes italianos instalados na região, possui potencial de revitalização que se iniciou com o moinho Colognese, restaurado e transformado no atual Museu do Páo, e tem como meta se expandir pelo território, consolidando o percurso de visitação aos moinhos locais.

O conceito de "lugar", por sua vez, transpassa diversas disciplinas, devendo à filosofia, à antropologia, à história e à geografia algumas de suas definiçôes essenciais. Em arquitetura e urbanismo, o conceito de "lugar" tem sido resgatado nos últimos anos e utilizado, em conjunto com noçôes de projeto e planejamento, com o objetivo de qualificar o meio ambiente construído.

$\mathrm{Na}$ geografia humana, destacam-se os estudos de YiFu Tuan sobre percepçáo ambiental de lugar. Tuan estabelece "espaço" como movimento e "lugar" como pausa. Para o autor, "espaço" é mais abstrato do que "lugar". O que começa como espaço indiferenciado transforma-se em lugar à medida que o conhecemos melhor e o dotamos de valor" (TUAN, 2013, p. 14). $\mathrm{Na}$ mesma área de conhecimento, Tim Cresswell define que "lugar", "no nível básico, é espaço investido de significado no contexto de poder. Esse processo de investir espaço com significado acontece ao redor do globo em todas as escalas, e tem ocorrido ao longo da história humana” (CRESSWELL, 2014, p. 35, tradução nossa).

Sendo tão associado aos significados e contextos de uma cidade, "lugar" é também muito relacionado com a noção de memória coletiva. O termo "lugar de memória”, criado pelo historiador francês Pierre Nora, no trabalho intitulado "Entre memória e História: a problemática dos lugares", evidencia a noção de "lugar de memória". Para Nora, lugar de memória pode

(...) tratar-se de um monumento, de uma personagem, de uma estátua ou pintura, de um museu, de arquivos, bem como de um símbolo, de um evento ou de uma instituição. Porém, nem tudo se caracteriza como lugar de memória; para isso o documento, o evento, o monumento etc., deve possuir uma "vontade de memória", deve ter na sua origem uma intenção memorista que garante sua identidade. (NORA, 1993, p. 9).

Para Heidegger (1994), "lugar” está relacionado ao ato de habitar. Segundo o autor, habitar compreende a transformação de espaço em lugar, atribuindo-lhe significado. Dentro da perspectiva da ArquiteturaUrbanismo, Edelweiss (2016), a partir do estabelecido por Heidegger, relaciona o lugar à memória:

O habitar, portanto, pode ser entendido como um ato sensível de memória, onde o habitante é capaz de estabelecer relaçóes entre os elementos postos em diálogo em diferentes cenários urbanos 
a partir de fragmentos de memória, seja por relatos presentes na memória coletiva transmitida de geração em geração, seja pelo patrimônio edificado. Este, por sua vez, carrega em si a memória de acontecimentos passados em um determinado contexto e contribui para a construção coletiva da memória do lugar a partir de uma complexa interpretação indissociada entre o tangível e o intangível. O patrimônio cultural, em sua complexidade e constante construção do lugar, é passível de significado para as pessoas que nele habitam e tem uma dinâmica temporal que deve ser compreendida. (EDELWEISS, 2016, p.154)

Ainda na perspectiva da Arquitetura-Urbanismo, cabe-nos ressaltar a definição de Castello (2007), para quem "lugar" se investe de significado através da "percepção de lugar". Para o autor um lugar de memória representa tanto o patrimônio construído, com sua importância histórica e arquitetônica, quanto também as memórias que as pessoas têm pela vivência no local. O lugar de memória é consagrado pela vivência comunitária e pelo acumular de memórias sobrepostas, de experiências individuais e compartilhadas.

(...) lugar é um conceito entendido em seu sentido de denotar uma qualificação que se atribui a um espaço através da percepção de suas potencialidades, objetivas e subjetivas (físicas e psicológicas) para a realização de experiências existenciais. (...) em termos gerais, pode-se dizer que lugar, na teoria arquitetônico-urbanística, é uma criação morfológica ambiental, imbuída de significado simbólico para seus usuários. (CASTELLO, 2007, p. 116)

Em termos operacionais, a produção de lugar, através de técnicas de projeto e planejamento que intervêm no meio construído, já apresenta extensa documentação. "Placemaking", termo mais difundido para nomear a produção de lugares, "refere-se a um processo colaborativo de moldar o domínio público para maximizar o valor compartilhado", sem deixar de atentar para as "identidades físicas, culturais e sociais que definem um lugar" (UNITED NATIONS..., 2015, p. 1).

Contudo, somente projetar e implantar uma ação de placemaking, muito mais voltada ao projeto e realização arquitetônicos em si, pode não ser suficiente para a criação de um lugar. Entram em campo, então, as atividades de "placemarketing", de modo a garantir o sucesso na aceitação de lugares recém-inventados por parte da população.

A utilização de preexistências também é estratégia corrente das açóes conjugadas de placemaking e placemarketing para a produção de lugares. Parte, entâo, para a apropriaçáo de edificaçóes ou conjuntos, com características reconhecidas pela cultura local, e potencializá-las em transformaçóes de projeto. Contudo, o cuidado com a memória é necessário, pois:

(...)as transformaçóes pressupóem uma pré-existência e é no respeito a ela que devem ser trabalhadas. Esse conceito de preexistência, para nós, no entanto, é mais do que uma mera imagem a ser recuperada, mas se refere a significados existenciais profundos que o lugar estabelece(CARSALADE, 2009, p.366). 
Muito se atribui o sucesso de museu a sua capacidade de constituir, de imediato ou ao longo do tempo, um marco referencial, um espaço privilegiado no desenvolvimento das açóes sociais dos habitantes de uma cidade, em outras palavras, constituir um "lugar". Objetos icônicos e de importância inegável, os museus utilizam processos de criaçáo de lugares (e são utilizados por estes). Museus dos mais variados tipos têm sido utilizados como instrumentos do processo de produção e gestão dos lugares e a "crescente proliferação de edifícios icônicos construídos dentro de preocupaçóes de placemaking e placemarketing está igualmente entrando para a história das cidades (...)" (CASTELLO \& SMIDT, 2012). É possível citar como exemplos o Museu Guggenheim, na cidade de Bilbao, na Espanha, e a Fundação Iberê Camargo, de Porto Alegre, no Brasil.

A utilização de preexistências para criação de novos lugares é prática comum em arquitetura e urbanismo: parte de reproduzir uma ideia original já presente (a aura do lugar) e potencializá-la pela açáo do projeto. Por outro lado, quando não há material, indaga Lerner, o que se faz? Para o autor, não seria o caso de fabricar e sim buscar algo que possa resgatar um momento e alavancar outros: seria uma acupuntura da memória.

A ideia de criação de lugar para o caso aqui estudado prescinde de uma extrapolação de escala: o Museu do Páo é parte de uma estratégia mais ampla, conectado a um sistema de lugares organizado pela ideia de resgate da cultura popular dos imigrantes italianos dispersos pelo território conhecido como Vale do Taquari. Lynch (1978) já havia demonstrado esta possibilidade em "Managing the Sense of a Region", de 1978, e Castello também explicita a relevância desta escala de lugar:
A importância da emergência de um sistema de lugares regionalizados, conformados por unidades espaciais que, apesar da massiva exposição aos fluxos espaciais globais, mantêm suas características peculiares, sua individualidade e sua identidade, fornece uma satisfatória ilustração do que seja uma dimensáo regional para o conceito de lugar. (CASTELLO, 2007, p. 257).

\section{Caminho dos Moinhos}

O Estado do Rio Grande do Sul apresenta um ótimo exemplo de criação de um conjunto de lugares regionalizados na Serra Gaúcha, agrupados sob a denominação de Região das Hortênsias, que exemplifica a geração coletiva de lugares moldados segundo as feiçôes de um enraizamento comum. $\mathrm{O}$ conjunto, brevemente citado no artigo a modo de ilustração, engloba lugares que se agrupam de forma mais ou menos coordenada, por vezes extremamente estruturada e por outras totalmente intuitiva. Por sua vez, o conjunto é composto por "lugares regionais" distintos: Vale dos Vinhedos, Gramado-Canela, São Francisco de Paula e Nova Petrópolis, por exemplo. A eficácia da estratégia regional pode ser comprovada pelo grande fluxo de turistas e pelo desenvolvimento econômico que proporcionou a toda regiáo.

No caso aqui apresentado, a estratégia regional foi elaborada enquanto o "Caminho dos Moinhos", pensada para resgatar do abandono um conjunto arquitetônico de antigos moinhos que se distribui pelo Vale do Rio Taquari. O projeto foi concebido por Marcelo Ferraz e Manuel Touguinha, a partir do trabalho de pesquisa de Judith Cortesão, que teria 
despertado a atenção de Marcelo, como o próprio relata em entrevista a Pachalski:

Em 2003 conheci Manuel Touguinha, amigo de Judith, que me levou para conhecer os tais moinhos, num passeio revelador e inesquecível. A partir daí, começamos (Touguinha e eu) a sonhar com a criação de uma rota, um caminho dos moinhos e, mais do que isso, com a festa do pão, com os pães... Elaboramos um primeiro estudo, para ter o que mostrar, e saímos a campo numa peregrinação em busca. (CORTESÃO, 2003)

A rota turística do projeto "Caminho dos Moinhos" envolveria a recuperação do Moinho Colognese (único já realizado) e outros cinco moinhos: Fachinetto, Marca, Dallé, Vicenzi e Castaman. Estes últimos receberiam programação específica, além da preservação das atividades de moagem. A professora e ambientalista Judith Cortesão, no ano 2000, foi quem primeiro apelou para a urgência das restauraçóes, pesquisas e divulgação dos moinhos coloniais. Tamanho entusiasmo da professora inspirou a criação da Associação dos Amigos dos Moinhos do Alto do Vale do Taquari (AAMoinhos) que busca conservar esse patrimônio. De lá para cá, já voltaram a funcionar alguns dos moinhos, como o Moinho Vicenzi, situado ao lado de uma cachoeira. No coração do Caminho, em Ilópolis, funciona desde fevereiro de 2008 o conjunto do Museu do Páo, compreendendo o Moinho Colognese, a Oficina de Panificação e o museu, que também será abordado neste artigo.

A AAMoinhos, formada pelos municípios de Anta Gorda, Arvorezinha, Ilópolis e Putinga, em parceria com o Instituto do Patrimônio Histórico e Artístico Nacional (IPHAN), promove o Ponto de Cultura chamado de "Páo, Cultura e Arte para todos". Seu primeiro ato foi adquirir a edificação do Moinho Colognese com recursos doados pela Nestlé Brasil através de um projeto da Lei de Incentivo à Cultura (LIC). Depois de recuperar o Moinho de Ilópolis, a associação pretende desenvolver o "O Caminho dos Moinhos" incluindo os municípios da Associação (Figura 1).

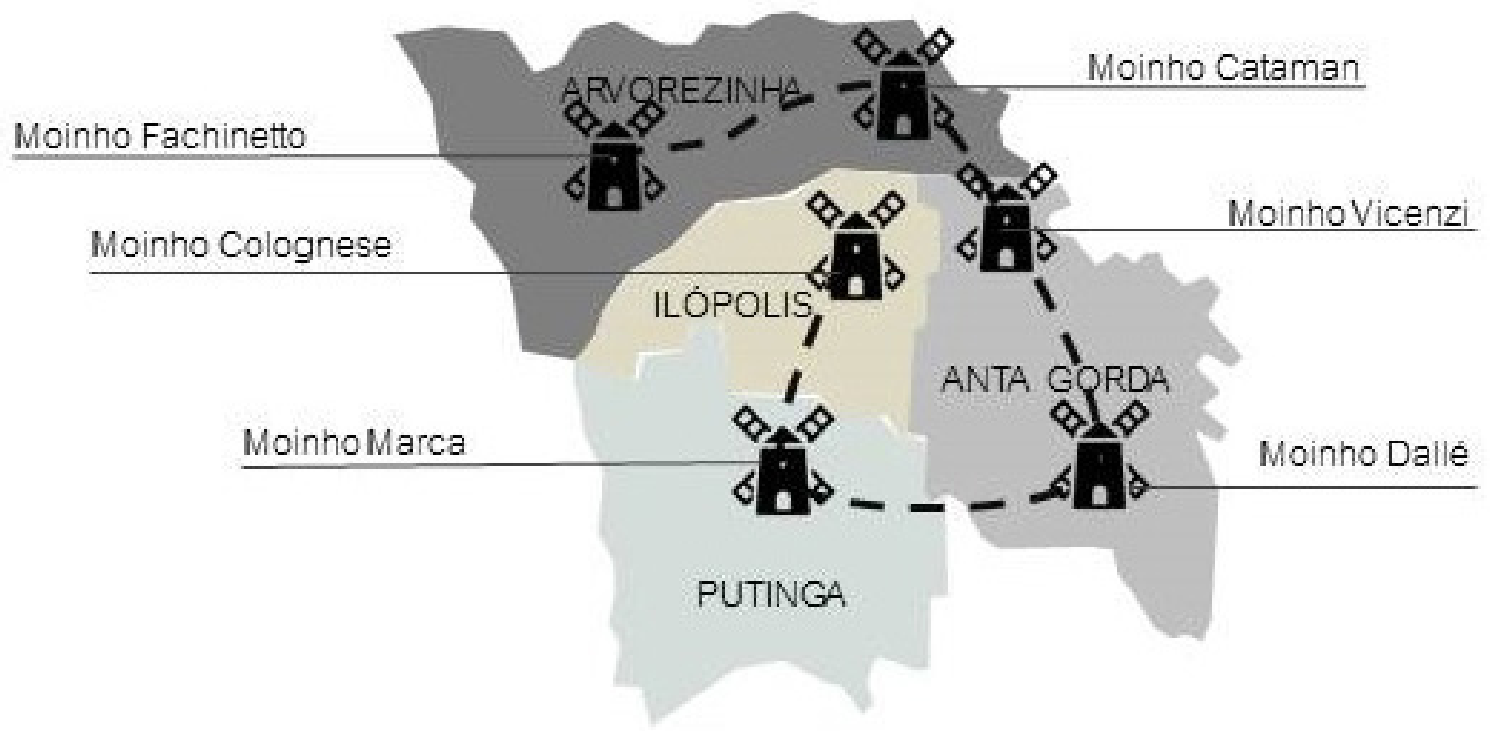

Figura 1: Caminho dos Moinhos.

Revista online do Departamento de Arquitetura e Urbanismo da Pontifícia Universidade Católica - 
O Museu do Páo, como parte da estratégia da constituição de um marco para o Caminho dos Moinhos, envolveu a recuperação do antigo Moinho Colognese e a criaçáo do próprio Museu e da Oficina de Panificação, que promovem o resgate das raízes da cultura local e a disseminação do conhecimento da produção da culinária local.

Neste sentido, a implantação do Museu é mais que o marco inaugural: é a "acupuntura" em escala da região, que marca com edifício icônico, programação e divulgação de atividades, o potencial de desenvolvimento regional. O Museu sinaliza a criação de um lugar, caminha na busca de manutenção da cultura e das características locais, ao mesmo tempo que insere o Vale do Taquari em uma rede de lugares regionalizados.

Os moinhos do Vale do Taquari, na serra gaúcha, são registros materiais e também imateriais da imigração italiana no Rio Grande do Sul construídos no início do século passado. Para as famílias italianas recémchegadas no Brasil essas construções de madeira reproduziam o retrato do trabalho humano. Essas instalaçôes representavam também a conquista de uma vida autossustentável, tendo o pão e a massa como base econômica e culinária.

O Museu do Páo é um exemplar de intervenção onde o gesto arquitetônico apresenta-se como um gesto em prol da preservação da memória cultural. A regiáo do Vale do Taquari, no Rio Grande do Sul tem em sua história, de colonização predominantemente de origem italiana, a produção de farinha e, portanto, ao longo do território conta com equipamentos capazes de representar uma parte da história da colonização do estado do Rio Grande do Sul, tendo no Museu do Páo o ponto de partida dessa representação.

Vendo aquelas casas, aquelas igrejas, de surpresa em surpresa, a gente como que se encontra, fica contente, feliz e se lembra das coisas esquecidas, de coisas que nunca soube, mas que estavam lá dentro de nós... (COSTA, 1995, p.15)

O trecho de Documentação Necessária de Lúcio Costa, elaborado primeiramente em 1929 a pedido de Manuel Bandeira na ocasião da edição comemorativa de um jornal mineiro e, logo após, em 1938, citado por Gilberto Freyre em Casa Grande e Senzala, ilustra a indissociável relação existente entre o patrimônio material e o patrimônio imaterial. No caso do Caminho dos Moinhos, são estes elementos, os antigos moinhos, que são capazes de simbolizar a narrativa histórica.

Castriota (2007) atenta para o entendimento contemporâneo de patrimônio ambiental urbano, contemplando as dimensôes histórica e cultural em suas complexidades.

É nesse sentido que nos parece fundamental o conceito contemporâneo de patrimônio ambiental urbano, matriz a partir da qual podemos pensar hoje a preservação do patrimônio, sem cair nas limitaçóes da visão tradicional. Pensar na cidade como um "patrimônio ambiental" é pensar, antes de mais nada, no sentido histórico e cultural que tem a paisagem urbana. (CASTRIOTA, 2007, p.17)

Edelweiss (2016) estabelece a importância do reuso de edificaçóes existentes no sentido da salvaguarda da memória cultural. E a partir deste entendimento, relacionando as transformaçôes sociais e seu impacto nas transformaçóes de lugares, que se insere a intervenção arquitetônica como estratégia de 
produção do lugar regional.

Estratégias como o reuso de edificaçóes existentes ou a requalificação de áreas urbanas ou conjuntos são capazes de ressignificar e transformar. Assim, a instrumentalização das estratégias é essencial, pois a transformação é capaz de afetar valores, sejam eles sociais ou, inclusive, econômicos. Portanto, estratégias desse porte devem levar em consideração a transformação urbana em todas as suas dimensóes, almejando salvaguardar valores sociais presentes na história da cidade. Os riscos de gentrificação, de transformação total das dimensóes social e histórica ou de transformação de lugares em não lugares — resultantes da substituição de usos são riscos inerentes a essas estratégias e devem ser criteriosamente considerados visando preservar o patrimônio cultural em seu sentido mais amplo. (EDELWEISS, 2016)

Segundo Júlio Posenato (1983), a arquitetura da imigração italiana se desenvolveu de maneira espontânea com características peculiares, feita por imigrantes italianos e por seus descendentes. Essa arquitetura tem como predomínio a simplicidade, o baixo custo e ornamentação singela. Segundo o autor, apresenta qualidade e racionalidade construtiva. Em seu estudo, Posenato identifica expressóes arquitetônicas próprias, tendência à simetria, limitando ao essencial os elementos construtivos. Aproveitando materiais locais, utilizase principalmente madeira, tijolos e pedra. São erguidas edificaçôes de até quatro pavimentos, com predomínio da mão-de-obra familiar e artesanal.
Os moinhos do Vale do Taquari são exemplares dessa arquitetura, ou pelo menos com resquício dela. As construções foram perdendo sua antiga função ao longo dos anos, podendo assim assumir novos papéis, como o exemplar Moinho Colognese, que se transformou no atual Museu do Páo.

\section{Museu do Páo}

O projeto do Museu do Pão, localizado em Ilópolis é de autoria dos arquitetos e urbanistas Francisco Fanucci e Marcelo Ferraz, do escritório Brasil Arquitetura e do arquiteto e urbanista Anselmo Turazzi, e data de 2007, com seu início em 2005. O conjunto da obra do escritório Brasil Arquitetura contempla demais intervençôes em preexistências, como o Theatro Plytheama em Jundiaí/SP de 1995, o Conjunto KKKK em Registro/SP de 1996, o Museu Rodin Bahia em Salvador/BA de 2002 e o projeto para o concurso vencido de Requalificação do Bairro Amarelo em Berlim na Alemanha de 1997.

O Caminho dos Moinhos e o Museu do Pão são parte de um conjunto de projetos que o escritório Brasil Arquitetura realizou no Rio Grande do Sul, a partir de 2000. Praticamente todos estes projetos envolveram preexistência de interesse arquitetônico cultural: Museu do Pampa, Revita São Leopoldo, Moinho Dallé: Bodega, Moinho Marca, Mercado Jaguarão, Memorial e Ateliê Valduga, SEDE da CDL Porto Alegre, Sistema Fecomércio e Restaurante Famiglia Facin (KNIES, 2008).

O projeto do Museu do Páo, apresentado em 2005 na publicação "Francisco Fanucci, Marcelo Ferraz: Brasil Arquitetura”, momento em que ainda estava em execução, posteriormente obteve como reconhecimento o Prêmio Rodrigo Melo Franco de Andrade na categoria preservação de bens móveis e 
imóveis, foi finalista no World Architecture Festival em Barcelona, e obteve também o Prêmio Rino Levi ex-aequo IAB em São Paulo; todos no ano de 2008.

Conforme exposto, a iniciativa do projeto do Museu do Páo, aliada à proposição de valorização cultural do Caminho dos Moinhos, constitui um primeiro passo no sentido da viabilização da rota cultural. $\mathrm{O}$ Moinho Colognese, por sua arquitetura, atua como patrimônio material e imaterial. Sua imagem é capaz, de maneira iconográfica, de representar a memória cultural da região. Neste sentido, entende-se a preexistência, por seu potencial iconográfico, como um elemento passível de salvaguarda e interesse cultural.

O programa do conjunto, englobando o Museu do Páo e a Oficina de Panificação, em novos volumes, e, ocupando o antigo moinho, inclui a as atividades de moagem retomadas, como demonstração, e uma bodega para eventos. Além da restauração do Moinho Colognese, o Museu do Páo resgata e divulga acervo de peças e utensílios ligados ao fazer do dia a dia dos colonizadores italianos. Os saberes intangíveis também têm seu lugar: a oficina de panificação retoma a prática do padeiro, forma novos profissionais e se propóe a desenvolver suas técnicas.

O partido parte da implantação de dois volumes novos, em concreto aparente, articulados em "L" e conectados por passagem aberta em madeira, típica das residências dos colonos italianos, que conformam a esquina pela ocupação do Museu e o fundo do lote, que se alinha ao curso d'água existente, pela Oficina (Figura 2). O museu, assim, tem seu programa dividido entre três edificações, duas delas contemporâneas, e a terceira preexistente, o moinho Colognese. As duas novas edificaçóes abraçam a preexistência de maneira sutil, possibilitando a criação de um percurso, permitindo ao visitante um passeio arquitetônico, que se inicia pela entrada na nova edificação que abriga o museu e o auditório, em seguida segue para a edificação da oficina de pães e por fim o moinho de madeira de araucária restaurado. Os volumes baixos de um pavimento deixam visível a presença vertical do Moinho, mesmo se interpondo entre esse e a esquina principal (figuras 3, 4 e 5).

$\mathrm{Na}$ implantação do conjunto, observa-se uma distância física entre o Moinho Colognese e os novos blocos (Figuras 2, 3, 4 e 5). Visivelmente detecta-se a diferença entre arquitetura do Moinho, em maior escala e protagonismo e a arquitetura dos novos elementos. A materialidade, no entanto, estabelece uma relação de diálogo entre a preexistência e o novo:

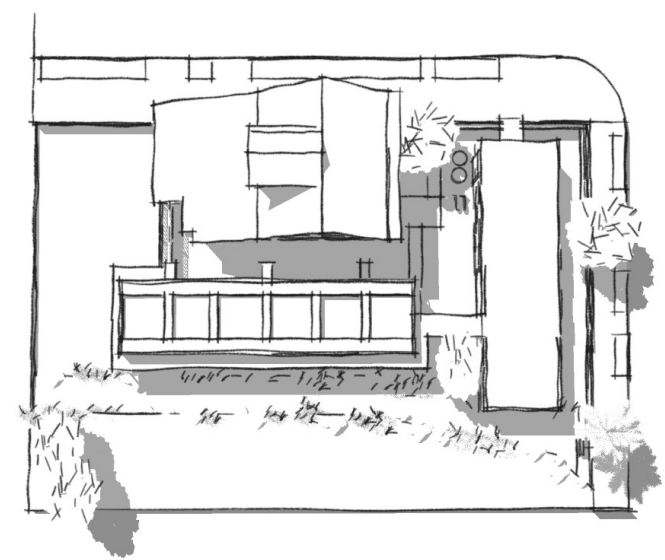

Figura 2: Implantação do conjunto. O Moinho Colognese ocupa o centro, junto à esquina está o Museu e paralela ao fundo do lote a Oficina.

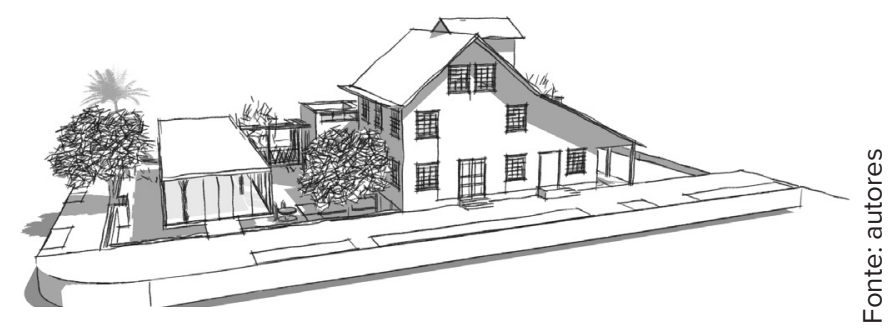

Figura 3: Vista do conjunto 


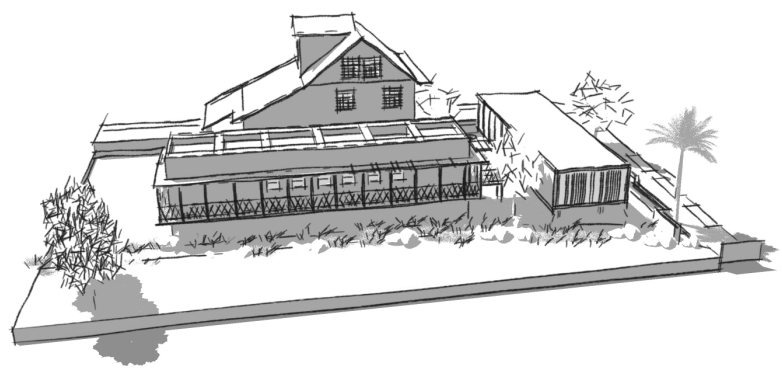

Figura 4: Vista de fundos, tendo a Oficina em primeiro plano e o Moinho Colognese ao fundo.

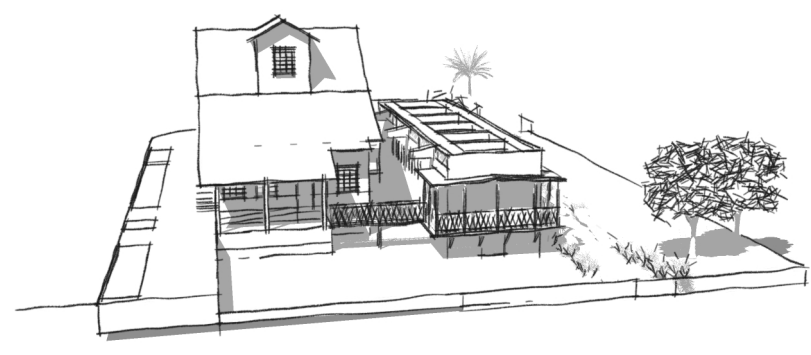

Figura 5: Vista leste, tendo o Moinho Colognese e a Oficina em primeiro plano.

o Moinho (Figura 6), construído de ripas de madeira de araucária, material em abundância no território e empregado pelos imigrantes na ocasião, e telhado de duas águas apresenta-se como referência para o gesto da intervenção.

O emprego de tecnologias como concreto armado, o vidro e a madeira, na intervenção, apresenta-se de maneira criteriosa ao relacionar o novo com o existente. $\mathrm{O}$ concreto armado, em sua fabricação, tem o emprego de fôrmas de ripas de madeira, estabelecendo um diálogo com o desenho das ripas verticais do Moinho existente (Figuras 7 e 8). Segundo os autores (FERRAZ e FANUCCI 2018) o projeto trata de uma "celebração da madeira".

Conforme apontam os projetistas, a salvaguarda do essencial da memória, frente à perda necessária, se faz presente: a Casa Roman, que foi comprada e demolida

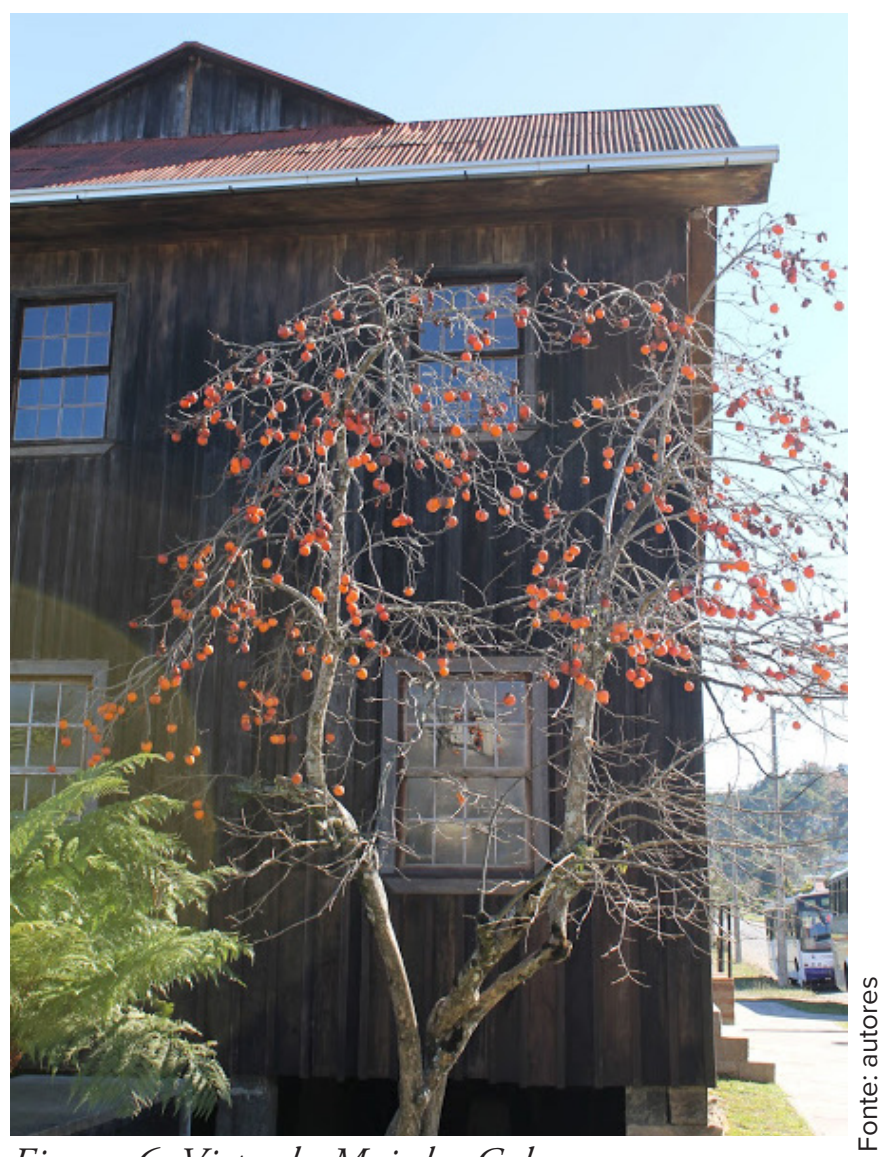

Figura 6: Vista do Moinho Colognese

para utilização de sua madeira na restauração do moinho, teve preservado um fragmento de parte da decoração da bodega, um painel de madeira, com desenhos à base de óxido de ferro e azul anil, de autoria desconhecida (FERRAZ, 2008). Os desenhos desse painel foram adotados como símbolo do Caminho dos Moinhos e gravados na fachada do Museu, como apresenta a Figura 8.

A planta livre, possibilitada pela tecnologia do concreto armado, aliada ao emprego do vidro, confere ao anexo transparência e contraste com o edifício do Moinho (Figuras 9 e 10). A madeira, por sua vez, é empregada nas conexóes entre os dois novos blocos de concreto armado e vidro e a preexistência. As passarelas ao ar livre representam uma distância física e temporal entre a preexistência e a intervenção. (Figura 11). 

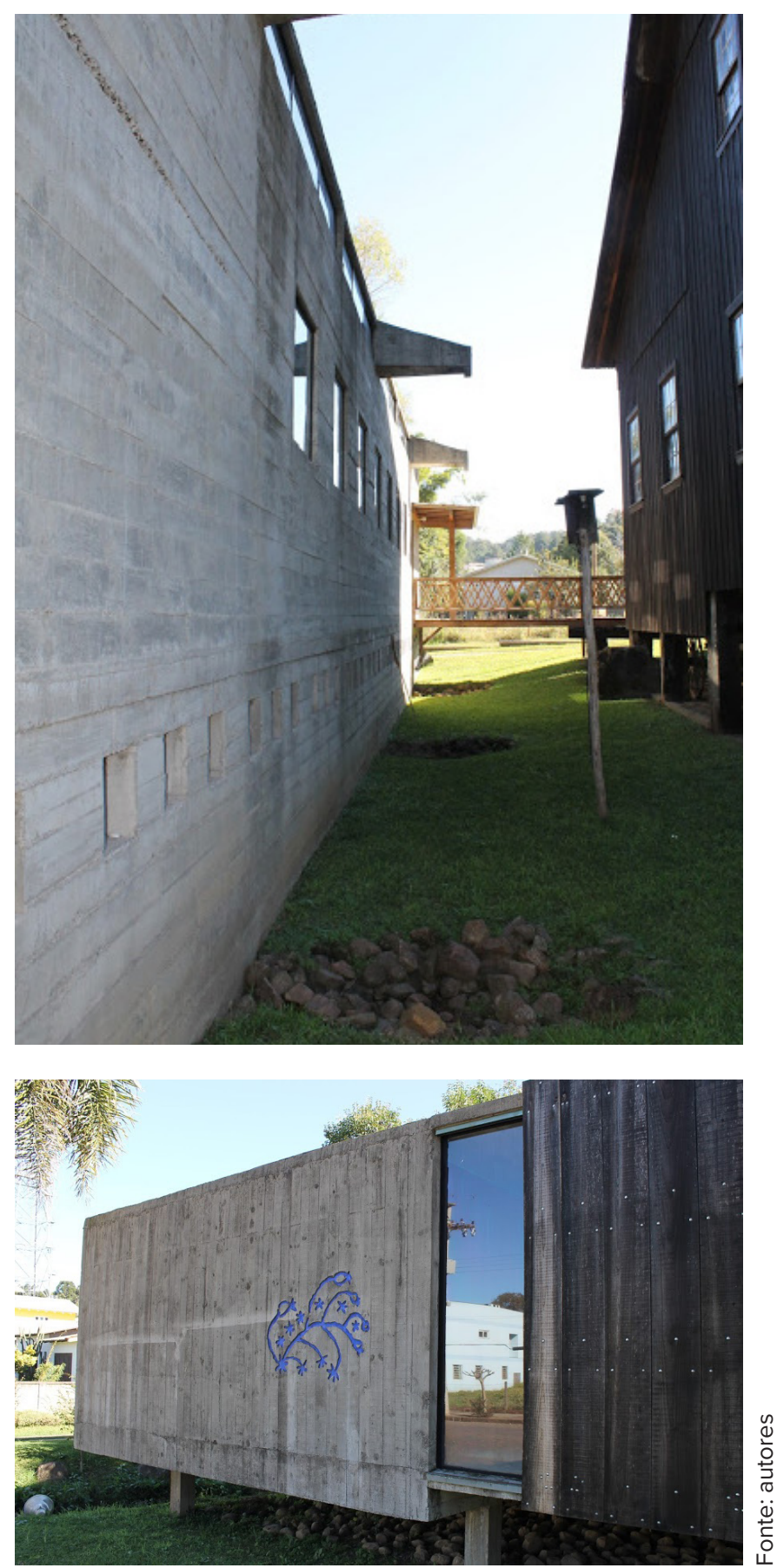

Figuras 7 e 8: Emprego do concreto armado nas fachadas.
Os arquitetos do Brasil Arquitetura, optaram por seguir a proposta tipicamente italiana do porão de pedra no pavimento do subsolo, fazendo um alinhamento do porão da construçáo preexistente com o subsolo proposto no bloco da oficina. Já na edificação do museu e auditório optaram pela elevaçáo do volume por meio de pilares assim como ocorre no porão do moinho Colognese.
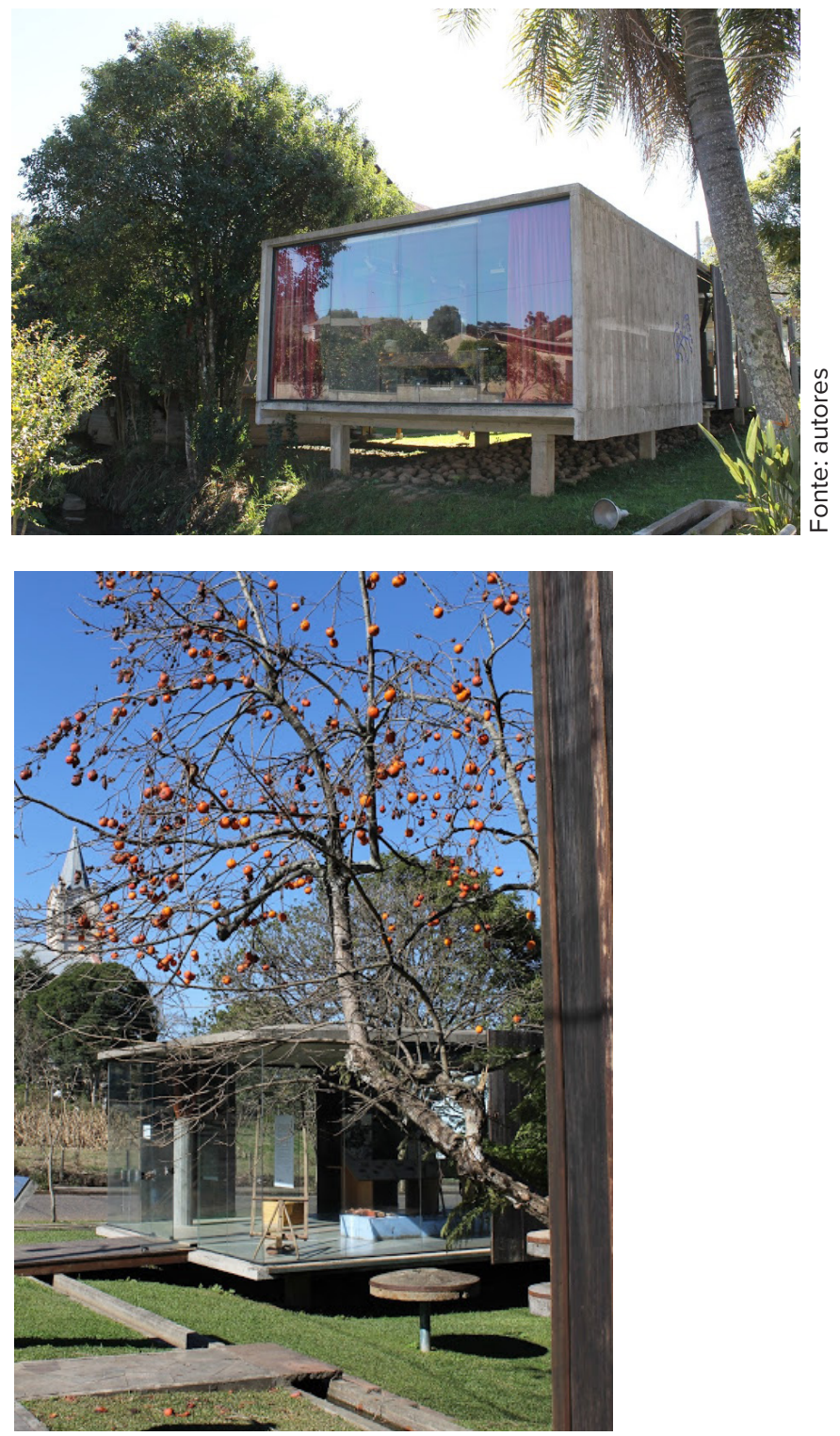

Figuras 9 e 10: Emprego do concreto armado nas fachadas.

Revista online do Departamento de Arquitetura e Urbanismo da Pontifícia Universidade Católica -

Puc-Rio - Rio de Janeiro Brasil

Ano I- No I - ISSN 2446-7340 


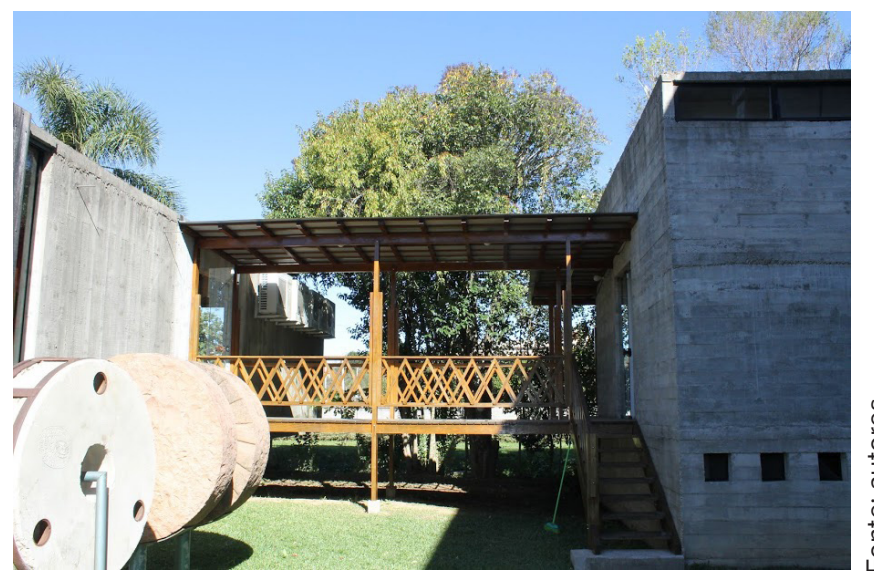

Figura 11: Passarela de conexáo entre os blocos.

A breve descrição, abordando principalmente a composição e a materialidade da intervenção arquitetônica do Museu do Páo vem ao encontro do gesto da revitalização. Em prol da memória cultural, em escala regional, a escala arquitetônica da edificação apresenta-se como um primeiro passo para o estabelecimento do Caminho dos Moinhos como rota cultural. Neste sentido, a escala de intervenção do projeto do Museu do Pão apresenta-se como uma metástase positiva, repercutindo no território.

\section{Conclusão}

Por meio desse artigo, pode-se concluir como o urbanismo e arquitetura são indissociáveis, uma vez que um trabalha em prol do outro. No caso do Museu do Páo nota-se a consonância de ambos, tendo no museu o ponto inicial para fazer com que o Caminho dos Moinhos se torne uma estratégia projetual possível e favorável para a regiáo do Vale do Taquari.

No tocante à memória cultural, apresenta-se a arquitetura de colonização e imigração no Vale do Taquari como patrimônio material e imaterial. A partir da estratégia de intervenção em um dos Moinhos apresenta-se o potencial para o estabelecimento do Caminho dos Moinhos. Neste sentido, o artigo buscou apresentar a relaçáo entre arquitetura e território, a partir da valorizaçáo do patrimônio material, traduzido em preexistências de Moinhos que representam a atividade produtiva da história da região.

Entende-se, portanto, a intervenção arquitetônica como estratégia para a produção do lugar na escala regional. $\mathrm{O}$ entendimento da intervenção, neste sentido, vem ao encontro do que se apresenta como "metástase positiva", ou como "acupuntura", uma vez que é capaz de promover a revitalização em escala territorial. 


\section{Referências bibliográficas:}

ALCALÁ, Laura Inés. Reflexiones sobre algunas estrategias urbanisticas en la ciudad de Barcelona durante el último cuarto del siglo $X X$. Cuaderno Urbano, Resistencia, $\mathrm{N}^{\circ} 5$, Junio 2006.

CARSALADE, Flávio de Lemos. Intervenção e restauro em arquitetura: um problema arquitetural.In: COMAS, Carlos Eduardo; PEIXOTO, Marta; MARQUES, Sergio M. (org.). O moderno já passado, o passado no moderno: reciclagem, requalificação, rearquitetura. Porto Algre: Ed. Uniritter, 2009.

CASTELLO, Lineu. A percepção de lugar: repensando o conceito de lugar em arquitetura-urbanismo. Porto Alegre: PROPAR-UFRGS, 2007.

CASTELLO, L.; SMIDT, L. Uma ideia resiliente na história do urbanismo. In: XII SHCU - SEMINÁRIO DE HISTÓRIA DA CIDADE E DO URBANISMO. 2012, Porto Alegre. Anais... Porto Alegre: PROPAR/PROPUR UFRGS, 2012.

CASTELLO, L. Repensando o Lugar no projeto urbano: variaçóes na percepção de Lugar na virada do milênio (1985-2004). 2005. UFRGS, [s. 1.], 2005, p. 313.

CASTRIOTA, L.B. Intervençóes sobre o patrimônio urbano: modelos e perspectivas. In: FORUM Patrimônio: ambiente construtivo e patrimônio sustentável, v.1, n.1, p.9-31, 2007.

COSTA, L. Registro de uma vivência. São Paulo: Empresa das Artes, 1995.

CRESSWELL, Tim. Place: An Introduction. 2. ed. [s.1.]: John Wiley \& Sons, 2014.

EDELWEISS, R. K. Cidade contemporânea, memória e preservação patrimonial: uma interpretação a partir das preexistências culturais. In: Revista Oculum Ensaios: revista de arquitetura e urbanismo, v.3, no.1, 2016. Disponível em:<http://periodicos.puc-campinas.edu. br/seer/index.php/oculum/article/view/322> Acesso em abril de 2018.FERRAZ, João Grinspum (coord.). Museu do Pão: caminho dos moinhos. Ilópolis: Associação dos Amigos dos Moinhos do Alto do Vale do Taquari, 2008.

FERRAZ, Marcelo e FANUCCI, Francisco. Depoimento. In: Museu do Pão / Brasil Arquitetura. Disponível em <https://www.archdaily.com.br/br/01-8579/museu-do- pao-moinho-colognese-brasil-arquitetura> Acesso em maio de 2018

HEIDEGGER, M. Conferencias y artículos: construir, habitar, pensar. Barcelona: Serbal, 1994. Cap.6, p.139142.

KNIES, Carolina Gottert. Brasil Arquitetura: Projetos e Obras no Sul. [Dissertação de Mestrado]. Programa de Pós-Graduação em Arquitetura e Urbanismo. UniRitter Mackenzie. Porto Alegre, 2015.

LERNER, Jaime. Acupuntura Urbana. São Paulo: Editora Record, 2011

LYNCH, Kevin. Managing the Sense of a region. Cambridge: MIT Press, 1978.

NORA, Pierre. Entre memória e história: a problemática dos lugares. Projeto História: Revista do Programa de Estudos Pós-Graduados de História, São Paulo, v. 10, out. 2012.

PACHALSKI, G. A. O MUSEU DO PÃO : Arquitetura, cultura e lugar. 2012. Universidade Federal de Pelotas, [s. 1.], 2012, p. 221.

POSENATO, Júlio. Arquitetura da Imigração Italiana no Rio Grande do Sul. Porto Alegre: Ed. EST Ediçôes, 1983.

TUAN, Yi.-Fu. Espaço e lugar: a perspectiva da experiência. Londrina: EdUEL, 2013.

UNITED NATIONS TASK TEAM ON HABITAT III. Habitat III Issue Papers 11 - Public Space. New York, 2015. Disponível em: <http://unhabitat.org/wp-content/ uploads/2015/04/Habitat-III-Issue-Paper-11__ PublicSpace-2.0.compressed.pdf>. Acesso em 20 de Abr. 2018. 